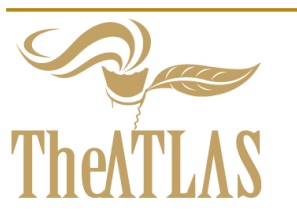

\title{
Rapid Urbanization, Ecology and Sustainability: The Need for a Broad Strategy, Holism and Transdisciplinarity
}

\author{
Gerardo del Cerro Santamaría, Gerardo del Cerro Santamara, Ph.D., Dr. Soc. Sci. U.S. Fulbright Award \\ Recipient in Urban Planning, New York, European Union Expert Committee on Urban and Regional Policy, \\ Email:gdelcerro@gmail.com \\ Received 16 September, 2019, Revised 23 October, 2019, Accepted 31 October, 2019 \\ Copyright (C) 2019 Gerardo del Cerro Santamaría. This is an open access article distributed under the Creative Commons \\ Attribution License (https://creativecommons.org/licenses/by/4.0/), which permits unrestricted use, distribution, and \\ reproduction in any medium, provided the original work is properly cited.
}

Available online 1 November, 2019 at www.atlas-journal.org, doi: 10.22545/2019/0128

to his paper questions the conventional approaches to "planetary urbanization," particularly their neglect to articulate the current process of rapid urban growth within the framework of new climate regimes and the ecological crisis. From this angle, it is irrelevant whether we focus on the idea of "city" or "the urban" in order to grasp contemporary socio-economic developments. Put differently, "planetary urbanization" is one of the fundamentally constitutive elements of the Anthropocene era. Planetary urbanization is a problematic concept, and one that does not allow us to seriously analyze and assess the ecological threat and begin to craft proposals for a better understanding of sustainable development practices. After suggesting that the idea of "ecology" is fundamentally opposed to the idea of "nature," we propose a concept of sustainability that is relevant for urban contexts and for an overall situation of planetary urbanization defined within the Anthropocene. Accordingly, an urban context will be defined as sustainable if it is planned and governed to account for the capacity, fitness, resilience, diversity and balance of its ecosystem. We take the view of sustainability as an organic process including environment, economy and community: form and efficiency (environmental factors in design, architecture, engineering and construction) as well as policy (urban plans and practices that explicitly aim at maintaining and improving the social and economic well-being of citizens). We need to step away from any conception of "the natural" as Nature. What is natural is what is sustainable, both urban and non-urban.

Keywords: Rapid urbanization, ecology, sustainability, anthropocene, megaprojects, green capitalism, strategic urban planning, transdisciplinarity. 


\section{Introduction (Planetary Urbanization?)}

Danish architect Bjarke Ingels recently declared: "I had to overcome the centrism that means identifying the city only with the beautiful streets that surround the historic center. The city, and the urban, is much more." [1] This is an apparently simple idea, easily intelligible and which surely many inexpert observers would agree with - the city, and the urban, is much more than a historic center. I focus on this apparent simplicity because it contains two concepts - the city and the urban - whose meaning and interpretation are far from obvious. Groups of planners and urbanists in the forefront of research have been debating about the primacy of one concept over the other in the last years. Has the reality of "the city" been subsumed in "the urban", as the French philosopher Henri Lefebvre argued in the 1970s? [2] And, if so, should we stop focusing on the study of "the city" and focusinstead on the study of "the urban"? What would this mean in practice?

Brenner \& Schmid (2011, passim) have provided a rich description of the massive urban changes underway. The concepts of "urban agglomerations," "cityregions," "urban regions," "metropolitan regions" and "global cities-regions" refer to a particular qualitatively specific, spatially delimited territory. Such territory is demarcable and different from "nonurban" spaces. However, there is growing evidence of the difficulty of spatially demarcating the urban from the non-urban.

In the first place, the creation of new urbanization scales in the last decades

"is a constant process that originates urbanized interdependencies, "urban galaxies," in rapid expansion, within very large metropolitan regions and also outside them. Such urban galaxies go from the formation and multiplication of incessantlygrowing polynucleated population clusters that cross, with increasing frequency, national border limits." [3]

Secondly, we also witness a functional rearticulation of urban territories. This implies that

"the "central functions" of earlier times, such as commercial facilities, corporate headquarters, research institutions, cultural places of prestige, as well as spectacular architectural constructions, dense settlement patterns and infrastructure systems are being dispersed from the historical central nuclei of the cities to former suburban spaces. Such new suburban locations locate between extensive basins of small and medium-sized cities, and along the main transport corridors such as highways and rail lines." [4]

Thirdly, a disintegration of the "hinterland" (semirural areas adjacent to cities) has been taking place all over the world. The old hinterlands of major cities, metropolitan regions and urban-industrial corridors

"are being reconfigured as they are assigned new functions." Such new functions include secondary offices and warehouses, industrial complex headquarters, recreational areas, generation networks, energy, resource extraction areas, fuel depots, waste disposal areas or connectivity corridors. The purpose of this process is to facilitate the continued expansion of industrial urbanization and its associated planetary urban networks." [5]

Finally, in all regions of the world, the old "natural" spaces are being transformed and degraded as a socio-ecological consequence of a global urbanization without restrictions. In this way,

"the oceans of the world, the alpine regions, the mountain ranges, the equatorial tropical forests, the tundra, the great deserts, the arctic and polar zones, and even the terrestrial atmosphere itself, are increasingly interconnected with the rhythms of the local, regional, national and global planetary urbanization. Even the spaces that lie beyond the traditional nuclei of cities and suburban peripheries have become integral parts of the world urban fabric from transoceanic sea lanes, transcontinental highways and global communications infrastructures to alpine and coastal tourist enclaves, parks, offshore financial centers, agroindustrial zones." [6] 
According to Neil Brenner and Christian Schmid (2011) the geohistorical transformations triggered by planetary urbanization

"pose a fundamental challenge to the entire field of urban studies: their basic epistemological assumptions, categories of analysis and research object require a fundamental reconceptualization to continue being relevant in the study of the massive transformations of the world socioeconomic reality that we are witnessing today, transformations that point towards the "urban" as an increasingly planetary condition, as Lefebvre pointed out forty years ago." [7]

Is this hypothesis tenable? Even if empirical transformations of the scale and scope described by Brenner \& Schmid are indeed taking place, would this massive transformation cause the obsolescence of the "city" concept for empirial research and theorybuilding? We believe that Brenner's and Schmid's approach is questionable on many fronts.

First, erasing the demarcation between what is urban and what is not, as seems to be suggested in a situation of "planetary urbanization," is very problematic for the researcher. In science, and in philosophy of science, the concept of "demarcation" is essential: it allows us to establish which scientific practices produce theories that can be considered valid epistemologically (Resnik, 2000). If the intention is to point out the limitations of the concept of "city" for empirical research, then it is not useful to propose to study instead a situation of complete urbanization without alternatives in empirical reality. We would say that the field of study proposed by Brenner and Schmid does not have a defined object: it deals with all reality and, therefore, with no reality. It is necessary to establish gradations and distinctions between what is urban and what is not. When this is not done, as in Brenner's \& Schmid's conceptualization, the concept of "planetary urbanization" defeats itself as a heuristic strategy.

Second, the "planetariness" of urbanization only leads to a speculative epistemological enterprise, as Sue Ruddick has pointed out: a proposal incapable of conceiving the emancipatory politics of a right to the city, of a policy that puts self-management and globalization at the forefront of research (Ruddick, 2015). If there is to be a systematic urban theory for our time, "it must emerge from difference, not universality; from ontological diversity, not epistemological hierarchies. Ruddick proposes not only that difference be recognized as a constitutive aspect of capitalism, but also to recognize the struggles for social ontology and everyday life as a hotbed of struggle, as the place where subjects are capable of transforming themselves and the world in which they live. [8]

Third, the "rural" is much more than something merely "non-urban." Ananya Roy maintains that the rural is a constituent element of the urban (Roy, 2015). This means that,

"even if we assume a process of planetary urbanization, we must explain analytically and empirically the processes through which the urban is constituted, experienced and disputed - as a circuit of capital accumulation, governmental category, historical conjuncture. In the case of "the rural," it is a question that encompasses regulations and rights that are not urban and are not simply opening a path for the urban. The social relations of production, as well as the political identities and struggles evident in such rural territories, cannot be encompassed by the urban. The processes of formation of the urban are, therefore, incomplete. We have to read the urban from the point of view of the absence. Such absence is not a negation or even an antonym; it is rather the undecidable." [9]

In sum, Brenner's and Schmid's effort to rigorously refocus urban studies is commendable. However, if we take their argumentation to its logical conclusions, it exhausts itself and perishes due to lack of demarcation criteria. This would cause, paradoxically, the dissolution of the field of study that these authors want to refound. The paradigm of planetary urbanization would then result in practice in a reformulated version of research into the political economy of global capitalism understood in a broad sense. The urban would disappear from the equation due to the absence of the non-urban. In short, once the process of planetary urbanization is accepted as a global empirical development, it seems inevitable to demarcate and limit our object of study and to 
continue using the old spatial concepts associated with "the city" in its different manifestations. It is not a matter of replacing "the city" with "the urban." We need to continue using both concepts in a dialectical and complementary way.

\section{Green Capitalism? A Strategy Bound To Fail}

The climate talks in Paris in December 2015 were characterized as humanity's last opportunity to respond to climate change (Tollefson \& Weiss, 2015). Many expected some kind of international agreement to be reached, and such an agreement took place, thus committing the world to significant reductions in greenhouse gas emissions. In this context, the fundamental question is not that the United States decided to withdraw from the Paris agreement, however significant this decision may be. Perhaps the fundamental issue is that "the much-advertised "solutions" of emissions reduction objectives and control of market mechanisms seem insufficient for mitigating or minimizing the terrible effects of climate change on the planet" (Järvensivu et al, 2018, 17).

"An important part of the funds for the Paris meeting came from the main fossil fuel companies and coal emitters. Though not particularly surprising, this fact hints at the fact that we are facing a deeper problem: the global economic system of corporate capitalism seems unwilling to reach the levels of decarbonization necessary to avoid the devastating effects of climate change." [10]

Gradually, the perspective of "creative selfdestruction" is spreading. Companies are trapped in a cycle of exploitation of the world's resources in increasingly irreversible ways. This is evident in the haste shown by some of the world's largest oil drilling companies in deep and arctic waters, oil sands processing, new coal mega-mines and "fracking" (currently in apparent decline), shales and coal seam gas.

"These examples highlight both the inventive genius of corporate capitalism and the blindness of industry and governments to the ecological degradation to which they are contributing." [11]
Despite the alarms coming from science, large corporations continue to exploit the environment by deliberately obscuring the link between endless economic growth and the worsening of the planet's environment. They typically succeed in challenging civil society and critical perceptions of the climate crisis. They tend to approach the problem as a matter of partisan debate instead of posing it as a social, economic and political problem that concerns the future of humanity. Moreover, through the narrative of "green capitalism",
"corporations and the market are perceived as the best instrument to respond to the climate crisis. According to this corporate image, the "green" products and services, the increase in ecoefficiency, and the inge- nious and technological domain of corpo- rate entrepreneurship will save us from a dark planetary future." [12]

In addition, citizens are portrayed as an active part of corporate campaigns, as consumers and "ecoentrepreneurs" in search of "green consumption." We are the brands we use, the cars we drive, the products we buy. In some way it comforts us, by familiarity perhaps,

"to find the future, perceived as "safe," in the hands of the market. The brilliant image of corporate environmentalism and corporate sustainability does not promise conflicts or compensations. In this vision it is possible to address climate change while continuing the current global expansion of consumption." [13]

According to this perspective there is no contradiction between material progress and environmental well-being. This is incessantly suggested to the public in unequivocal and persuasive ways. By proposing that corporate initiatives are capable of solving environmental challenges, the conciliatory vision of "green capitalism"

"also fits well with the dominant economic and political paradigm of our time - neoliberalism. Alternatives to laissez-faire capitalism, such as state regulation and mandatory restrictions on the use of fossil fuels, are considered counterproductive and even harmful." [14] 
The dominant narrative implies that there is no alternative to the market. It conveys the impression that it is easier to imagine the end of the planet than the end of capitalism. Such is the supremacy of our current capitalist imagery, which exercises powerful control over our thinking and our actions. It is a power strengthened by the promotion of each new "green" product, a power exercised through the establishment of the controlled discourse of sustainability in business and politics.

Ultimately, the "success" of the climate talks in Paris in the coming years may be irrelevant to challenging the fundamental dynamic underlying the climate crisis. This is so because it seems clear that radical decarbonization based on putting limits on consumption, economic growth and corporate influence is not subject to debate. On the contrary, the global elites have chosen an accentuation of these tendencies. Until the economy, finance and politics take responsibility for what science establishes, the domination of corporate capitalism will ensure the progressive degradation of our habitable climate.

Investors and shareholders naturally seek to maximize the return on their investments, which requires growing sales and a greater consumption of resources by citizens. Chairmen of corporate boards have tried to deal with this problem in two ways, both of which involve avoiding the problem and continuing with business as usual. One way to deal with the matter, by the most ideologically aggressive companies, such as ExxonMobil, has been to finance those who deny the climate problem. Paradoxically (perhaps not so much), Exxon is drilling oil in the Russian Arctic thanks to the warming they deny (Barron, 2019) [15]. The other corporate way to deal with the matter has been to recognize that the problem is real, and try to appear more "sustainable" for environmentally conscious customers, employees and investors by adopting

"an "ecological" approach, thereby reducing waste and introducing recycling. They market "green" products such as organic foods, less toxic household cleaning products, light bulbs and low-energy appliances, etc. They put solar panels on roofs, and so on. "Green" production has not really altered the fundamental corporate priority of growth and profits over the environment." $[16]$
Does it really matter, for example, "if Ford Motor Company produces hybrid cars and covers the roof of its car plants with solar cells, when they continue to produce cars, which are millions and millions of global heaters? In order to save humans, what we need is not electric cars, but a lot of fewer cars," as Naomi Klein $(2015,43)$ contends [17]. Is Ford going to kill itself in order to save humanity? ... We may want and need phones, but phones cannot be sustainable if they are disposable. However, how can Apple stay in business if it stops producing disposable products? We need more radical strategies to save the planet. For example, we ought to work towards transforming corporations from entities with the only purpose of private profit into multi-purpose institutions with obligations to the public at large. We ought to consider a transformation in tax systems, from taxing income to taxing non-ecological, polluting practices. Regrettably, even investors and companies that show sensitivity to the environmental problem remain silent about the possibilities just mentioned.

Can green capitalism save the planet? The idealism of green capitalism can serve as a middle ground between the motive of economic gain and the ecologically sustainable use of the planet's natural resources. The extrapolation of the immediate consequence of climate change to the likely scenario of near extinction can be a particularly alarming way of motivating people to action, but it could be effective. In any case, the basic ecological contradiction of capitalism is not easy to solve: the maximization of profit and the salvation of the planet are inherently in conflict, even if both sets of interests overlap at times. The business world embraces environmentalism as long as this move increases profits. However, saving the planet requires that the pursuit of profit be systematically subordinated to ecological concerns, and, despite what is at stake, this is not a reasonable expectation, at least for the time being.

\section{Ecology and Nature}

Everyone who loves nature fears losing it. However, "nature" is not "the other" in an increasingly urban world, but rather a new way of thinking about the sustainable integration of all sentient beings and the environment. What we call "environment" is always a mixture of nature and culture. People and landscapes are molded together. Nature and culture re- 
semble hydrogen and oxygen in water: together they create new and exciting possibilities. Nowhere is this interaction better expressed than in cities. To discover how this idea can work in the "Anthropocene" (the contemporary era of massive and radical transformation of the planet by human beings), we need study and transformation, vision and practice. We need an "urban practice of the natural" that, as suggested by the American poet and environmental activist Gary Snyder (2008), combines

"the knowledge of Western philosophy, poetry and natural sciences with the wisdom and spiritual techniques of Native American and Asian cultures." [18]

The old ways that supported human life for a hundred thousand years acquire a new and fundamental relevance in the achievement of a sustainable world. But how can we practice the natural in cities? Isn't it a contradiction in terms? It is not, although it requires a change of mentality. The "natural" does not necessarily mean "nature."

"The natural is about creativity, emergence and the self-organizing power of complex adaptive systems. The natural is the preservation of the world, i.e., sustainability, and this attitude is necessary especially in cities. If so, then we must align our thoughts and efforts accordingly, beginning with education. Sustainability requires ecological literacy, so let's incorporate it into the curriculum from elementary school to university. Each neighborhood of a city is full of lessons about natural and human history, a living museum that lacks signage and teachers. It's all there." [19]

Cities also offer a splendid place for imaginative ecological designs and to articulate a vision of the "ecology of reconciliation," in which the built environment would be configured to meet the needs of multiple species in addition to ours. It is not difficult to extend this idea in many directions (Barriere et al, 2019) [20]. Inspiring instances can already be found in many cities, including New York,

"where the High Line Park was created along the bed of an abandoned elevated railroad and "pocket parks" have emerged in brownfields or vacant lots along the River Bronx and other neglected places. Such projects, accessible and designed at a human scale, are often promoted and maintained by people in the neighborhood. Let's insist that what matters is a change of mentality and perception. For this purpose it is helpful to think about the ideal of the city as a work of art." [21]

The idea of art as a form of autonomous individual expression (as opposed to craftsmanship made in the name of a patron, be it king or church) "arose at the same time as the romantic notion of nature." [22]

"In the Romantic tradition, which includes most of the avant-garde, art is directly related to nature under the guise of the creative genius that replaces academic conventions and other forms of external control. Both art and nature are, therefore, ways to repair the damage that society has inflicted on the individual and the environment. However, while nature is something that is "out there," art is the human production closest to us." [23]

The urban is art, or it can be. It is a place where the existential state of physical matter that comprises the universe existing beyond our attempts to rule over it can be revealed virtually at the intersection of physical matter and the conscious being. The city is true nature in all its frightening and inanimate alterity, a physical representation of the relation of the objective form and the subjective content that constitutes a work of art.

The romantic vision of nature, the aesthetic idealization of the exurban areas, has had disastrous consequences for the ecological health of the planet. The invasion of wild areas in distant places allows us to justify our abuse, neglect or exploitation of local nature, which seems less dignified and less atrocious to victimize. The ideal of "wild" or "natural" life contributes to situate the urban as deserving of aesthetic contempt, and induces urbanites to tolerate, on a daily basis, many of the problems of cities. The human conscience is trapped in a mode of romantic ecological consumption that makes the forest a showcase and allows the environment of a showcase to be experienced as the temple of nature. This is the reason why we consume the desert and the forests (Heynen et al, 2006). [24] 
City and nature are in fact closely interrelated ideas. Both are organized and distant complexity of self-regulated harmony. The concept of nature as an autonomous and harmonious set of internal self-regulated relationships that always return to harmony and equilibrium insofar as they are not disturbed by man or humanity is a misconception Nature is, in fact, a waste without measure.

"No doubt, at this moment, there is a black hole that devours a solar system that contains a planet with a rich ecosystem and that includes the emergent life of the intelligent octopus that will soon enter the space age and explore the rest of its solar system. Each season, the fish produce millions of offspring with only a few survivors. Throughout natural history, there have always been species that have had the advantage of unbalancing everything. This happened, for example, with the emergence of eukaryotes that filled the oxygen atmosphere making it flammable and causing the extinction of millions of species due to the decrease of several dioxides in the atmosphere. Asteroids hit the Earth, annihilating millions of species, and so on." $[25$

Let us reflect on the idea that nature as a harmonious, wise and self-regulating mechanism of Mother Earth is identical to the idea of the capitalist market. The neoliberal ideology says that the economy is a self-regulated system that always returns to balance and harmony. To intervene in this system, according to history, is to interrupt it and invite disaster by not obeying the anonymous wisdom of the economy (Polanyi, 1944) [26]. The case is similar in ecology. Because nature is considered harmoniously self-regulating, any technological intervention in the climate is considered a probable catastrophe (a subject of many science fiction-driven novels and films).

Moreover,

"let us remember that Darwin does not celebrate the harmony of nature, but how small differences can suddenly become significant differences as a result of geographic drift and climate change, but also how all kinds of cross-species and cross-species relationships generate new vectors of evolution that lead to completely surprising directions." [27]

Something very similar to what happens in the city as organized complexity. Therefore, "urban ecology" is the way of thinking about the natural in the contemporary era. The anthropocentrism that underlies the dominant ecological vision does not treat nature as a community to which we belong but as an external ideal that must be saved ... to save ourselves. This is the main ideological obstacle that prevents the achievement of sustainability.

\section{Urbanization's Threats to Ecology}

In the West and in other advanced regions of the world, the top-down planning of urban culture and the attempts to design or re-design cultural capitals via mega-projects have become in the last two decades the preferred policy choice of urban and regional leaders (del Cerro Santamara, 2017) [28]. The paradigmatic case of Bilbao is reproduced, among many other places, in Sydney, Hong Kong and AbuDhabi. To be sure, each city presents its own specific elements, even if environmental sustainability problems have characterized construction of megaprojects in most cities. Because of these challenges, both the West Kowloon Cultural District (WKCD) project in Hong Kong and the Guggenheim Abu-Dhabi project attracted significant criticism already during their design phase (del Cerro Santamara, 2017) [29].

Criticism also included the fact that iconic architecture has ceased to be the hegemonic visual discourse in urban revitalization. Further, the franchise model imposed by the Guggenheim (in the case of Abu-Dhabi) means that local leaders do not have autonomy to make important decisions regarding exhibition calendars, budgets and investments. In addition, local cultural identities are generally neglected under a global art model managed from the outside. Megaproject environmental impacts have been significant in both Hong Kong and Abu-Dhabi, and also in Sydney. The Abu-Dhabi project has also been the subject of controversy around workers' rights and working conditions. The WKCD, even without a Guggenheim, reproduces all the controversies associated with iconic megaprojects: cost overruns, negative environmental impacts, gentrification risks, drawbacks of elitist cultural engineering, 
neglect of local cultural identities and uncertainty regarding economic success of the megaproject. We need to also mention that the urban "visibility" strategy pursued by means of the design of megaprojects may not have a significant impact beyond the city where it is built. Whatever positive consequences there may be, they tend to benefit local-regional commercial interests and the interests of political and economic elites, instead of the majority of the population, as Susan Fainstein has shown (Fainstein et al, 2008) [30].

In Sydney, the Olympic Village of the 2000 Games was built in Homebush Bay, in an area where chemical plants had previously thrown a large amount of waste to the ground: dioxins and chemicals produced by Union Carbide Operations. From 1907 to 1988 , this site housed the State Slaughterhouses and the State Brick Factory, which included a clay and schist quarry. In the mid-1980s, when the brick factories and slaughterhouses were at the end of their working life, the area was designated for redevelopment (a typical case of revitalization of a "brownfield"). At the time of starting work for the Olympics, the area was surrounded by chemical plants, fuel terminals, petroleum products, an oil refinery, a prison and an industrial landfill. To remedy the situation, the cleaning process involved treating or eliminating contaminated soil. The Council for the Environment and Conservation of Australia and New Zealand (ANZECC) and the National Council for Health and Medical Research (NHMC) provided guidelines for dealing with contaminated sites, even if their main strategy was to move the problem elsewhere (Beder, 1993) [31].

These agencies advised soil treatment in situ, but the strategy adopted for Homebush Bay was limited to the removal of contaminated soil to a more polluted area in order to free space for the development of the Games's facilities. When Sydney presented its bid for the Olympic Games, Greenpeace Australia's design of a green Olympic park was chosen as one of the five winners and influenced the guidelines for the Olympic Village. However, even though an Environmental Advisory Panel was established as one of the six advisory panels for the organizers of the games, it was later dissolved, and its replacement apparently lacked sufficient legitimacy and authority In addition, the ecological guidelines established by the environmental committee were weakened by the Australian Olympic Committee in order to make them more feasible and simple, and this hindered the adoption of reliable assessment objectives that could have had some impact (Kearins \& Pavlolich, 2002) [32].

In Abu-Dhabi, in order to accommodate the new Guggenheim Museum (to be opened in 2017, but delayed), along with the Louvre and a Performing Arts Center, large tracts of land were removed and recovered. A breakwater has been built in the area of Al Saadiyat, the island that has become the new cultural district of the city. Frequently, breakwaters stagnate ocean flow and cause environmental problems. When the flow stagnates, neither waste nor nutrients can flow out of the immediate area, and this usually deteriorates the quality of the environment along the coast. Turbidity and sedimentation levels along the coasts of Saadiyat Island have also increased, according to local ecologists and oceanographers, and this is further damaging aquatic life. In addition, dredging activities in Al Saadiyat have adversely affected sensitive marine communities, including mangroves, seagrasses and coral communities in the area (Taelman, 2009) [33].

It is likely that the mangroves located within the boundaries of the recovery areas in Al Saadiyat suffer from both land reclamation and dredging. Both mangroves and seagrasses are very sensitive to the salinity and acidity of the surrounding water. Coral communities are very sensitive to sediment loads in surface waters coming from semi-impervious surfaces, such as roads, and transport mixtures of water containing contaminants. These waters are finally discharged into the coast, with obvious damage to coral communities and marine biodiversity.

In Hong Kong, the West Kowloon Cultural District (WKCD) has been built by recovering land (about 40 hectares) in Victoria Bay. According to the reports of the coordinating authority of the WKCD, the construction phase included polluting activities such as water run-off, pumped groundwater discharge, drainage diversions, sewage effluents and accidental spills that contained high levels of suspended solids and chemical products such as oils, solvents and materials derived from cement (Chan, 2000) [34].

The dredging process is necessary to eliminate the inadequate foundations and replace them with large volumes of dredged sand, which aggravates water pollution. The dredging affected the marine ecosystem around Hong Kong, which depends on the plants for sustenance. There was also a loss of 
filtering organisms: scallops, mussels and oysters, which are essential for the traditional Hong Kong fishing business. There is evidence that Chinese white dolphins, a species in danger of extinction in Hong Kong, are threatened by dredged materials. There are only 85 Chinese white dolphins remaining out of the original 300. It is expected that many of those that remain will die (Chan, 2000) [35].

On the other hand, during the preparatory construction for the WKCD, excavation activities, movement of vehicles, cement processing and loading and unloading operations worsened the already poor air quality in the area. The additional roads and parking lots in the WKCD are also affecting the quality of the air surrounding the area. When the WKCD becomes fully operational, it is very likely that the pollution resulting from traffic congestion will aggravate the existing problem of atmospheric pollution (WKCDA, 2013) [36].

Evidence from the three cases discussed - Sydney, Hong Kong and Abu-Dhabi - suggests that much remains to be done to reconcile urban development with ecology. Urban and regional governance has the potential and capabilities to move forward in environmenal sustainability policy in a faster and more effective way than national governments. From this perspective, it is reasonable to expect green cities and regions to multiply and proliferate, even if the hegemonic "green capitalism" narrative would hardly alleviate the dark planetary horizon that lies ahead.

\section{Thinking About the Future}

While research on rapid urbanization via the megaprojects phenomenon has grown steadily to the point of becoming an emergent discipline in its own right, little is known about the relationships between megaprojects and urban sustainability, in particular about the particular megaproject governance arrangements that foster sustainability. Urban sustainability can be generally defined as the idea that a city can be organized so that it meets the needs of the present without compromising the ability of future generations to meet their own needs.

The implications of all of the new dynamics for the livability of city regions have not found their way in generating new regional planning approaches. Instead,

\begin{abstract}
"governments adjust plans to accommodate private sector plans on an ad hoc projectby-project basis. While this can be seen as being realistic in the face of formidable processes of globalization and neoliberal governance, the greatly increased stress on the urban environment suggest the need for more proactive responses to environmental deterioration and flooding." [37]
\end{abstract}

In lieu of integrated planning, various levels of government in many metropolitan regions around the world
"are moving forward with more targeted re- sponses such as disaster preparedness, river clean-ups and improvements in water con- trol infrastructure. The outstanding ques- tion is whether such sector projects and programs sum up to a coherent strategy that can effectively address the portent of rising human costs of environmental dam- age." [38]

In the case of urban megaprojects, it is necessary to look beyond the "iron triangle" of fulfilled schedule, budget, and specifications in analyzing megaprojects.

\begin{abstract}
"Big projects need to be judged for how they meet objectives over time, amid shifting societal, political, and environmental values. Measuring the success of a megaproject is not linear. There are twists and turns not only in terms of engineering and the emergence of new technology, for example, but in the moving target of public expectations. New problems always crop up that such projects are expected to solve, long after the first blueprints were approved. The biggest plans tend get started under political leaders who are almost always gone by the time of completion." [39]
\end{abstract}

\section{A Focus on Sustainability}

Urban sustainability as a concept dates its first appearance in 1968 in an article written by Stanley A.Cain with the title "The importance of ecological studies as a basis for land-use planning." The author explores the contribution of land use \& planning to urban sustainable development and stresses the 
importance of ecological studies as a planning tool (Zhang \& Li, 2018) [40]. Vojnovic (2014) argues that the three pillars of sustainable development, namely society, economy, and environment

"can be equally promoted through the concepts of inter-generational and intragenerational equity. The first is concerned with maintaining the quality of natural ecological systems and their services over time, while the second is based on promoting the equitable access to resources within current generations, providing human populations with basic needs." [41]

Hannan and Sutherland (2015) propose six principles as a tool to assess the extent to which urban megaprojects recognize urban sustainability. These include:

"a) create of a place with a vibrant culture, where a diversity of social, environmental, and economic activities can take place, b) ensure social justice and contribute to intragenerational and inter-generational equity including the recognition of social, environmental and cultural heritage, c) ensure adequate community participation and democratic governance, d) ensure urban spatial integration and promote more sustainable and efficient forms of transport, e) promote economic growth and employment creation and ensure economic viability, and f) minimize pollution and waste; maximize energy efficiency and maintain ecological integrity." [42]

A megaproject can be defined as sustainable if it is planned and executed to take into account the capacity, suitability, resistance, diversity and balance of its urban ecosystem. We consider sustainability as an organic process that includes the environment, the economy and the community: form and efficiency - environmental factors in design, architecture, engineering and construction- as well as policies - urban plans and practices that explicitly aim to maintain and improve the economic well-being of citizens (del Cerro Santamara, 2018) [43].

An exploration into the conditions for sustainable urban governance in urban megaprojects will help us to critically evaluate the urban megaproject phenomenon and it will contribute to an understanding of the mutual relationships between globalization, urban development and sustainability. To be sure, suggesting that urban megaprojects could foster sustainability in cities is a counter-intuitive idea, but the growing importance of UMPs in globalizing cities warrants a balanced analysis in order to assess and show whether and how urban leaders foster sustainable urban practices even as they face pressures from investors and promoters to keep building.

From the viewpoint of sustainability, what specific controversies can urbanization via urban megaprojects trigger at various socio-political scales? What are the challenges, and what are the most suitable governance arrangements, that can be key for supporting the sustainable city? We try to address these questions by focusing on the case of China, a country experiencing significant environmental challenges due to rapid development via infrastructure investment. This discussion points towards various kinds of sustainable strategies, as we will discuss below: environmental, socio-economic, institutional, as well as those associated with the design, planning and management aspects of megaprojects.

\section{Infrastructure and Environmental Challenges in China}

Infrastructure and megaprojects have opened the door to socio-economic development in China. While the socioeconomic results are indisputable, China's performance in the area of environmentally sustainable development leaves room for improvement. According to the PRC Ministry of Ecology and Environment (PRCMEE),

\begin{abstract}
"two-thirds of China's lakes have chemical deficiencies caused by pollution. As a result of pollution and increasing consumption, two-thirds of China's cities are short of potable water. Air is heavily polluted across the northern heavy industry belt from Shanxi to Liaoning provinces and along the heavily industrialized east coast. Many polluted industrial sites will require extensive soil remediation before they will again be fit for human use." [44]
\end{abstract}

According to a New York Times report, China is responsible for $47 \%$ of the world's coal burning, which is more than all other countries in the world combined. As a result, 
11respiratory diseases that are directly related to air pollution are currently the leading cause of death in China, according to the World Wildlife Fund (WWF). In addition to some of the worlds worst air pollution, China also has many waterways that are highly polluted. According to the Economist, more than $50 \%$ of Chinas surface water is not fit for human consumption, whereas approximately 60

\subsection{Energy}

According to the World Bank,

"Electricity production in China doubles nearly every 10 years. China now generates 18 percent of all electricity globally, only slightly less power than the United States. China's non-fossil fuel electrical power sources are still overwhelmingly nuclear and hydro (96 percent combined), according to the World Bank. The more difficult target to achieve will be 20 percent renewable power production by 2020 . Despite rapid growth, wind and solar energy sources still make up less than one percentage point of total electricity production in China. Since solar power is still more expensive to produce than electricity from coal-fired turbines, the government offers subsidies either for capital investment or operations, but neither subsidy is sufficient to break-even under current conditions."

In addition to renewable power generation, there is a growing market for energy service company (ESCO) projects,

"which can help to reduce energy consumption and greenhouse gas emissions. ESCO projects typically finance the purchase of new energy-efficient equipment through projected savings on future fuel bills in comparison with old or energy-hungry machinery. While the World Bank and many smaller "green funds" have already entered this market, many local investors are hesitant, since they find the five-to-10 year payback period too long. This is one factor contributing to opportunities for foreign energy savings companies with local partners." $[47]$

\subsection{Water and Wastewater}

Future efforts to increase water sector performance should adopt a more integrated approach.

"The different components of urban water systems-water, wastewater, and stormwater-are often handled by different government organizations with different, sometimes competing agendas. Integrated water resource management can be used to match water quality to water uses, improve treatment cost-effectiveness, and raise the quality of discharged water to environmentally safe levels. China's water industry will open up for reverse osmosis, membranes, and other advanced treatment technologies that minimize energy inputs and simplify operations." [48]

\subsection{Transportation}

Transit-oriented development (TOD) is key in the development of Chinese cities. To be sure, land use and density factors are not yet considered systematically during design. However,

"many cities retrofit their zoning codes after subway construction to allow development to cluster around transit stops. With the right land use mix, this offers the possibility of higher use of non-motorized transport. At least 13 Chinese cities currently have one or more subway lines under operation, 54 lines covering $1,700 \mathrm{~km}$. Another 76 lines, or an additional 1,600 km, are under construction. The target is 40 subways systems by 2020 covering about 7,000 $\mathrm{km}$. At this pace and scale, TOD is poised to make a big difference in the long-term sustainability of urban living." [49]

\subsection{Desertification}

According to Smith,

"China is also dealing with rampant soil erosion and desertification, which is a type 
of land degradation that is a result of previously fertile soil transforming into arid land due to poor agricultural practices and land management, as well as extreme climate change. Both desertification and soil erosion cause blinding dust storms and riverclogging mud that have battered Chinese cities located near the edge of the Gobi Desert. According to the WWF, desertification has already swept over $30 \%$ of China's land mass. Since 1978, the Chinese has followed guidelines set by the Three-North Shelter Forest Program, otherwise known as the Great Green Wall, which involved the construction of what is now over 66 billion trees that are used to block the path of the Gobi's storms. Despite this afforestation project, the deserts expansion continues to affect various surrounding cities." $[50]$

And Schwärzel argues that,

"As towns continue to get swept under sand as a result of these storms, the Chinese government is forced to move affected populations away from degraded lands. In fact, between 2003 and 2008, over 650,000 people who were previously living in Chinas Inner Mongolia province were forced to resettle in other cities. An even more concerning fact is that these sand dunes are forming only about 44 miles away from Beijing at a pace of almost 2 miles each year. To prevent the capital city from being submerged in sand, the Chinese government must investigate new and creative ways in which natural ecosystems can be restored." [51]

\section{Governance for Sustainable Megaprojects}

As we have seen in our analysis of megaprojects in key global cities, these megastructures have significant environmental impacts, and thus attaining acceptable levels of environmental sustainability needs to become a priority for planners, developers and other stakeholders. However, the attainment of environmental sustainability does not in itself ensures megaproject sustainability, a goal that needs to be pursued holistically. One way to do it is to use the notion of "key or multiple success factors" (Grunert \& Ellegaard, 1992) [52].

This notion is not new in the field of project management and, in fact, constitutes one of the topics most discussed by specialists. It is increasingly important "to evaluate projects and their impacts at different times and based on multiple criteria in order to fully evaluate their performance. Success is often driven by political and/or power-related factors. [53]" Due to the strongly political nature of the stakeholders throughout the supply chain and their different underlying objectives, the success factors usually considered no longer seem sufficient. This configuration requires innovative governance solutions that align the interests of the different stakeholders in a complex environment with a large number of key actors (Harris, 2017) [54].

By following the notion of "multiple success factors," we contend that there are a number of requirements that need to be met in order to achieve sustainable megaprojects: environmental sustainability (sustainable infrastructure delivery and sustainable development zones); sustainability in design and planning; sustainability in megaproject management; institutional sustainability; and socio-economic sustainability. Thus, a megaproject can be defined as sustainable if it is planned and executed to account for the capacity, fitness, resilience, diversity and balance of its urban ecosystem. We take the view of sustainability as an organic process including environment, economy and community: form and efficiency (environmental factors in design, architecture, engineering and construction) as well as policy (urban plans and practices that explicitly aim at maintaining and improving the social and economic well-being of citizens).

\subsection{Sustainable Infrastructure Delivery}

Cities now have the opportunity to raise the bar of urban infrastructure delivery to safeguard the natural environment and open the door to the next phase of socioeconomic development. "As cities and countries climb the industrial
value ladder and expand their service sec-
tor to cater to growing domestic demand,
environmental quality will become central
to achieving sustainable economic growth.
Urban residents in the more sophisticated 
markets are already putting a substantial price premium on high-quality urban environment. To attract the right labor pool, cities will need to raise their game further." [55]

The backbone of the next phase of infrastructure development

"should be the "one-system" approach. Infrastructure planners need to consider the development of the entire city-wide infrastructure system, including its energy, transport, land, and water subsystems. Realizing the potential synergies between subsystems will require technology for real-time information, conservation pricing, and demand management." [56]

Foreign infrastructure providers and experts with strong track records in these areas should be poised to make a major contribution to achieving higher infrastructure performance standards in the coming years.

"Government stimulus and financing will also be critical. Central governments can redouble its commitment to environmental sustainability by continuing to pursue aggressive resource conservation and economic productivity targets, and by backing those efforts up with funding for investment in infrastructure." [57]

\subsection{Sustainable Development Zones}

Some countries such as China have taken steps to designate "sustainable development zones." Earlier this year, the Chinese government approved three sustainable development zones, which will implement the United Nations 2030 Sustainable Development Goals: Shenzhen, Guilin and Taiyuan.

"Shenzhen is Chinas innovation engine. This zone will integrate technologies in sewage treatment, waste utilization, ecological restoration, and artificial intelligence to solve issues from resource management to pollution. Guilin will focus on innovations that tackle desertification, creating solutions that can be replicated by other regions facing the threat of encroaching deserts. In Taiyuan, targeting air and water pollution, this zone will foster innovative solutions that can be replicated by regions relying on resource extraction." [58]

\subsection{Sustainable Planning and Design}

The planning of megaprojects should be oriented towards socially progressive goals and to ensure sustainable development rather than focus exclusively on growth and competition. The financial planning of megaprojects ought to avoid strategic misrepresentation of costs and benefits, and there should exists clauses ensuring a fair distribution of benefits for the community at large. In the design process of megaprojects, contextual elements such as history and local culture should be important factors to interpret the architecture and to assign a specific meaning (local, regional, national, global) to the architectural practices used to build megaprojects and make them visible (Del Cerro Santamaría, 2013). [59]

\subsection{Sustainable Management}

The management of megaprojecs ought to avoid the "exclusivity bias" between planners and managers, who tend to see their projects as unique, which prevents them from learning from other projects.

"Often there is an excessive commitment to a certain project concept at an early stage, resulting in a "block" or "capture", which makes the analysis of alternatives unlikely and leads to ad hoc commitments in later stages. The achievement and delivery of the megaproject is a high risk stochastic activity, with overexposure to the so-called "black swans", that is, extreme events with massively negative results. Managers should keep this in mind, instead of treating the projects as if they really existed in a deterministic Newtonian world of cause, effect, and control. Complexity and unplanned events need to be taken into account; budgets and time contingencies must adequately address them." [60] 


\subsection{Institutional Sustainability}

When studying megaprojects in connection with urban growth coalitions, we can ask ourselves if the form of development represented by these large projects simply legitimizes growth machines and commercial interests or if this phenomenon can be analyzed from the prism of the role that actors and state agencies play in urban restructuring. Besides growth coalitions, the governance of megaprojects needs to take into account additional stakeholders in order to ensure institutional sustainability. There is no room in this paper to adequately develop this argument, but I will simply mention the following aspects that would need to be taken into account: (1) the role of civil society; (2) the role of local context, history and culture; (3) the importance of keeping urban variety and diversity; (4) the importance of megaproject local embeddedness; (5) the role of public space; (6) the role of urban design professionals.

\subsection{Socio-Economic Sustainability}

The embeddedness of the multiple scales of socioeconomic action has paradoxically come along with a tendency towards providing megaprojects with their own strategic spatial planning tools that funcion independently of state and urban regulations. Thus, aligning the goals of megaprojects with regional and national policies has become an urgent necessity. New institutional arrangements between administrative levels, vital for implementing strategic policies, need to emerge, due to the negative results of separating the objectives of the megaprojects from regional and national policy goals.

Therefore, megaprojects, which usually work as catalysts of urban development, should be used at the national level as tools to advance sustainability policy. The result can be an optimization of sustainable policy outcomes due to synergistic, multiplier effects. From this perspective, the key question for future research would be how to plan and build urban megaprojects that simultaneously foster both sustainability and competitiveness.

\section{Conclusions: Strategy, Holism and Transdisciplinarity}

A major effort to stop the effects of climate change and support environmental sustainability has been developed around the world at the urban and regional levels around the concept and practice of the "sustainable city" and its associated planning practices. Planning schools around the world have included "sustainability" as one of their essential interests and today it is difficult to find professionals and academics who are not concerned with sustainable cities and the impact of climate change and global warming on the practices of urban planning. Urban systems have the potential to be more sustainable than suburban or rural communities. Therefore, it could be said that urbanization shows a potential to facilitate the management, and perhaps control, of climate change. The difficult challenges to achieve it come, not from the cities, but from the incentive structures of the capitalist system.

The notion of "strategic urban planning" has become paramount in efforts to address sustainability challenges in urban environments. This notion involves a holistic approach to problem-solving in the area of sustainability that implies placing the idea of complexity at the forefront of analysis and action. Complex thought, education and knowledge, in Edgar Morin's understanding, take into account contextual, global and multidimensional factors to desvise strategy conducive to more fruitful action.

"Pertinent, knowledge must confront complexity. Complexus means that which is woven together. In fact there is complexity whenever the various elements (economic, political, sociological, psychological, emotional, mythological ...) that compose a whole are inseparable, and there is interretroactive, interactive, interdependent tissue between the subject of knowledge and its context, the parts and the whole, the whole and the parts, the parts amongst themselves. Complexity is therefore the bond between unity and multiplicity. Developments proper to our planetary era confront us more frequently, ineluctably with the challenge of complexity." [61]

Complex knowledge also factors in the centrality of the knowing subject in analytical endeavors, 
the uncertainty of the knowledge enterprise itself and the incompleteness and undecidable nature of homo complexus's human action. Through complex knowledge, the holistic quality of urban planning neturally leads to a transdisciplinary conception of theory-building and practice development.

Thus, a possibly fruitful way to apply this notion of strategic urban planning would be to propose a transdisciplinary paradigm to address urban challenges. Strategy by itself is insufficient if it is based on traditional approaches to knowledge generation. A global and transdisciplinary strategy of sustainable development is required. The concepts in individual disciplines are not necessarily univocal. The global problems of sustainable development consist not only in some of the environmental problems (generally known as climate change and loss of biodiversity), but also in socio-economic issues, whatever exactly "sustainability" and its possible and multiple interpretations, involves politics, resources and power. Most current attempts to solve sustainable development are not conducive to sustainable development; they are mostly contradictory, inconsistent and inefficient. This contrasts with the nature of the behavior of sustainable development systems, which is non-linear and holistic.

"Green reformism" is based on a paradox, because it simultaneously adopts neoliberal capitalism and rejects economic growth. Although "green reformism" has developed an integral form of natural resource management, it has a poorly defined vision and well-being of human development. The current consideration of sustainable development in literature and the media is basically reductionist and involves mainly a binary thought. The problem is that reductionism, binary logic and disciplinary approaches are beliefs that must be overcome.

A transdisciplinary way of thinking is in order. Such a way of thinking would cross traditional disciplines and would modify the classical notion of science. A new vision fostering sustainable principles requires a rethinking of human values, and a reconsideration of the integration among the flow of perception, experience and consciousness. It is impossible to imagine a single solution to the problem of sustainability, but many complex, interrelated and evolving solutions. To avoid current destructive human behavior, we need to develop a new collective perception of human relations towards the valorization of a new set of attitudes and behaviors or towards a different prioritization of the set of current values. Holistic and unified knowledge can deal with complex global problems of sustainable development. Progress has been made in this regard and continues to be made, within the United Nations and in other forums and institutions. If, in addition, a rethinking of the priorities and structures of economic incentives is achieved, then we can say that there may be a space for hope.

Note: An earlier versin of this paper was accepted for the IEREK Conference on Future Smart Cities, Kuala Lumpur, Malaysia, November 2019.

Funding: This research received no external funding.

Conflicts of Interest: The author declare no conflict of interest.

\section{References}

[1] Ingels, B. (2018), cited in Chayka Kyle, The Brand Builder, The New Republic, May 2, https://newrepublic.com/article/147816/brandbuilder-bjarke-ingels-architect-designing-future. Retrieved May 6th, 2019.

[2] Lefebvre, H. (1970). La reévolution urbaine. Gallimard, Paris; Lefebvre, H.(1989) Quand la ville se perd dans une mtamorphose planétaire, Le Monde Diplomatique, May, 16-17.

[3] Brenner, N. and C. Schmid (2011). Planetary urbanization. In M. Gandy (ed.), Urban Constellations, Jovis, Berlin, p. 21.

[4] Ibid. P. 23.

[5] Ibid. P. 24.

[6] Ibid. P. 26.

[7] Ibid. P. 32.

[8] Ruddick, S. (2015). Situating the anthropocene: planetary urbanization and the anthropological machine. Urban Geography, 36(8), pp. 1113-1130, p. 1125 .

[9] Roy, A. (2015). What is urban about critical urban theory. Urban Geography, 37(6), pp. 810-823, p. 816.

[10] Järvensivu, P. et al, (2018). Global Sustainable Development Report 2019 drafted by the Group of independent scientists, BIOS Research Unit, Finland, https://bios.fi/biosgovernance_of_economic_transition.pdf. Retrieved May 6th, 2019.

[11] United Nations (1987) Bruntland Report, Chapter Two, United Nations World Commission on Environment and Development, 
https://en.wikisource.org/wiki/Brundtland_Report/ Chapter_2._Towards_Sustainable_Development. Retrieved May 6th, 2019.

[12] Yadong, Y (2013). Eco-efficiency trends in china, 1978-2010: decoupling environmental pressure from economic growth. Ecological Indicators. 24, pp. 177184, p. 181. doi:10.1016/j.ecolind.2012.06.007. Retrieved May 7th, 2019.

[13] Polman, P. (2019). A Business Model for Sustainability, World Economic Forum, https://www.weforum.org/agenda/2019/01/abusiness-model-for-sustainability/. Retrieved May 7th, 2019.

[14] Pyke, T. (2017). The energy debate: renewable energy cannot replace fossil fuels, Development Education, https://developmenteducation.ie/feature/theenergy-debate-renewable-energy-cannot-replacefossil-fuels/. Retrieved May 7th, 2019.

[15] Barron, J. (2019) How Big Business is Hedging Against the Apocalypse, The New York times, April 11, https://www.nytimes.com/interactive/2019/04/11/ magazine/climate-change-exxon-renewableenergy.html. Retrieved May 7th, 2019.

[16] Ferguson, P. (2018). Post-Growth Politics. A Critical Theoretical and Pokicy Framework for Decarbonization, New York: Springer, p. 53.

[17] Klein, N. (2015). This Changes Everything. Capitalism vs. The Climate, New York: Simon and Schuster.

[18] Snyder, G. (2008). cited in Dana Goodyear, Zen Master. Gary Snyder and the Art of Live, The New Yorker, October 20, https://www.newyorker.com/magazine/2008/10/20/ zen-master. Retrieved May 10th, 2019.

[19] Kang, W. (2019). Perceived Barriers to Implementing Education for Sustainable Development among Korean Teachers, Sustainability, 11 (9), p. 26. https://doi.org/10.3390/su11092532. Retrieved May 10th, 2019.

[20] Barriere, O. et al (2019). Coviability of Social and Ecological Systems: Reconnecting Mankind to the Biosphere in an Era of Global Change, New York: Springer

[21] Olsen, D. J. (1986). The City as a Work of Art. London, Paris, Vienna, New Haven, CT: Yale University Press, p. 21.

[22] Haskins, C. (1989). Kant and the Autonomy of Art. The Journal of Aesthetics and Art Criticism, 47(1), pp. $43-54$, p. 43.

[23] Ibid. P. 48.

[24] Heynen, N. et al (2006). In the Nature of Cities. Urban Political Ecology and the Politics of Urban Metabolism, London and New York: Routledge
[25] Morton, T. (2007). Ecology Without Nature. Rethinking Environmental Aesthetics, Cambridge, MA: Harvard University Press, p. 46.

[26] Polanyi, K. (1944 [2001]). The Great Transformation. The Political and Economic Origins of Our Time, New York: Beacon Press.

[27] Morton, Ibid. P. 81.

[28] Del Cerro Santamara, G. (2017). Iconic Urban Megaprojects in Global Context: Revisiting Bilbao, pp. 497-518 in The Oxford Handbook of Megaproject Management, edited by Bent Flyvbjerg, New York and London: Oxford University Press.

[29] Ibid.

[30] Fainstein, S. et al (2008). Megaprojects in New York, London and Amsterdam. International Journal of Urban and Regional Research, 32 (4), pp. 768-785.

[31] Beder, S. (1993). Sydney's Toxic Green Olympics. Current Affairs Bulletin, 70(6), pp. 12-18.

[32] Kearins, K. and K. Pavlovich (2002). The Role of Stakeholders in Sydney's Green Games. Corporate Social Responsibility and Environmental Management, 9(3), pp. 157-69.

[33] Taelman, E. (2009). Saadiyat Island Tourist Develoment Project: Dredging and Reclamation Works in an Ecologically Sensitive Area. Terra et Aqua, 116, pp. 3-11, September.

[34] Chan, Y. (2000). Reclamation and Pollution in Hong Kong with Special Reference to Victoria Harbour, The HKU Scholars Hub, http://hdl.handle.net/10722/36319 . Retrieved May 10th, 2019.

[35] Ibid.

[36] WKCDA (2013) Annual Report, http://www.westkowloon.hk/en/the-authority/ annual-report-20122013, Retrieved June 2019.

[37] Douglass, M. (2010) Globalization, Mega-projects and the Environment: Urban Form and Water in Jakarta, Environment and Urbanization Asia 1 (1), p. 18. https://doi.org/10.1177/097542530900100105. Retrieved June 2nd, 2019.

[38] Ibid. P. 21.

[39] OMEGA Center (2012). Mega-Projects: Lessons for Decision-Makers. An Analysis of Selected International Large-scale Transport Infrastructure Projects. Bartlett School of Planning, University College London.

[40] Ibid., p. 144.

[41] Ibid., p. 144.

[42] Hannan, S.,\& Sutherland, C. (2015). Mega-projects and sustainability in Durban, South Africa: Convergent or divergent agendas? Habitat International, 45(P3), 205212, p. 208. 
[43] Del Cerro Santamara, G. (2018). Megaprojects, Sustainability and Competitiveness in the United Arab Emirates, Fulbright Scholar Project Proposal.

[44] PRCMEE (2016) China's National Plan on Implementation of the 2030 Agenda for Sustainable Development, Ministry of Ecology and Environment of the People's Republic of China, http://english.mee.gov.cn/Resources/Plans/Plans /201803/P020180316511712813464.pdf. Retrieved June 6th, 2019.

[45] Watkins, D. K.K. Rebecca Lai And Keith Bradsher (2018). The World, Built by China, The New York Times, Nov. 18, B3, https://www.nytimes.com/interactive/2018/11/18/ world/asia/world-built-by-china.html. Retrieved June 6th, 2019.

[46] World Bank (2018). China - Systematic Country Diagnostic : towards a more inclusive and sustainable development (English). Washington, D.C. : World Bank Group. http://documents.worldbank.org/curated/en/ 147231519162198351/China-Systematic-CountryDiagnostic-towards-a-more-inclusive-andsustainable-development. Retrieved June 8th, 2019 .

[47] Bachmann, John and Joe Burnett (2012). Infrastructure and the Environment in Chinese Cities: Prospects for Improvement, China Business Review, July 2012, https://www.chinabusinessreview.com/infrastructureand-the-environment-in-chinese-cities-prospectsfor-improvement/. Retrieved June 8th, 2019.

[48] Southerland, D. (2017). China's Global Infrastructure Initiative Raises Environmental Concerns, Radio Free Asia, September, https://www.rfa.org/english/commentaries/chinaobor-09292017160823.html. Retrieved June 8th, 2019.

[49] Luo, Z. et al (2017). Pollution and Road Infrastructure in Cities of the People's Republic of China, Asian Development Bank Institute Working Paper no. 717, p. 41. https://www.adb.org/sites/default/files/publication/ 239581/adbi-wp717.pdf. Retrieved June 9th, 2019.

[50] Smith, B. (2018). China: Environmental Issues, Policies and Clean Technology, AzoCleanTech, July 24th, p. 32, https://www.azocleantech.com/article.aspx?ArticleI $\mathrm{D}=546$. Retrieved June 9th, 2019.

[51] Schwärzel, K. (2017) China's fight against desertification should not be done at the cost of wter security, The Conversation, October, https://theconversation.com/chinas-fight-againstdesertification-should-not-be-done-at-the-cost- of-water-security-83678. Retrieved June 9th, 2019 .

[52] Grunert, K. G. and C. Ellegaard (1992). The Concept of Key Success Factors. Theory and Method, MAPP Working Paper no. 4, October, ISSN 09072101, https://pure.au.dk/portal/files/32299581/wp04.pdf. Retrieved June 11th, 2019.

[53] Ibid., p. 28.

[54] Harris, M. (2017). Competitive Precinct Projects. The Five Consistent Criticisms of "Global" Mixeduse Megaprojects. Project Management Journal, 48(6), pp. 76-92.

[55] World Bank (2018). China - Systematic Country Diagnostic : towards a more inclusive and sustainable development (English). Washington, D.C. : World Bank Group, p. 32. http://documents.worldbank.org/curated/en/ 147231519162198351/China-Systematic-CountryDiagnostic-towards-a-more-inclusive-andsustainable-development. Retrieved June 12th, 2019.

[56] Ness, David (2018). Sustainable urban infrastructure in China: Towards a Factor 10 improvement in resource productivity through integrated infrastructure systems. The International Journal of Sustainable Development and World Ecology, 15 (4), pp. 288-301, p. 297.

[57] United Nations (2016). Executive Summary of China's Actions on the Implementation of the 2030 Agenda for Sustainable Development, Voluntary National Review 2016, https://sustainabledevelopment.un.org/memberstates /china. Retrieved June 12th, 2019.

[58] XinhuaNet (2018). China Approves Three Demonstration Zones on sustainable Development, February 2018, http://www.xinhuanet.com/english/201802/24/c_136997243.htm. Retrieved June 13th, 2019.

[59] Del Cerro Santamaría, G. (ed.) (2013). Urban Megaprojects. A Worldwide View, Bingley, UK: Emerald Publishing.

[60] Flyvbjerg, B. (2014) What you should know about megaprojects and why. An overview. Project Management Journal, 45(2), pp. 619. Retrieved from https://doi.org/10.1002/pmj. Retrieved June 13th, 2019.

[61] Morin, E. (1999). Seven Complex Lessons in Education for the Future, Paris: UNESCO, p. 19. 


\section{About the Author}

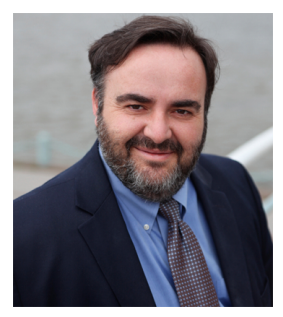

Gerardo del Cerro Santamaría is a U.S. Fulbright Award Recipient in Urban Planning from New York and a member of the European Union Expert Committee on Urban and Regional Policy. He has been a Visiting Professor at MIT and a Visiting Scholar at Columbia University, as well as Research Professor of Planning and Megaprojects at The Cooper Union for the Advancement of Science and Art in Manhattan, where he also served as Senior Executive Director of Strategic Planning and Innovation. He has been an Invited Professor of Urbanism and Globalization at the School of Architecture and Planning, Shenyang Jianzhu University and served as a Senior Advisor to the Planning of the Jing Jin Ji Megalopolis in China. Del Cerro has published several books, journal articles and encyclopedia entries. He is the author of Bilbao. Basque Pathways to Globalization (2007); editor of and contributor to Urban Megaprojects. A Worldwide View (2013); and author of "Megaprojects in Global Context" in The Oxford Handbook of Megaproject Management (2017). He has a background in Science, Music Theory, Logic and Philosophy of Science and holds Ph.D.'s from the New School for Social Research in New York (Political Economy) and the Universidad Autónoma de Madrid, Spain (Economic Sociology). 